\title{
Cancer risk among glass factory workers: an excess of lung cancer?
}

Risto Sankila, Sakari Karjalainen, Eero Pukkala, Hanna Oksanen, Timo Hakulinen, Lyly Teppo, Matti Hakama

\begin{abstract}
A total of 3749 workers employed for at least three months in two Finnish glass factories (cohorts $A$ and $B$ ) were followed up for cancer in 1953-86 through the Finnish Cancer Registry. In cohort A (1353 men, 1261 women), 106 primary cancers were diagnosed among men, and their standardised incidence ratio (SIR) for all cancers was 99. Among women the risk was low (65 cases, SIR 64$)$. In cohort $B(450$ men, 685 women), the relative risk of cancer was close to unity for both men (57 cases) and women ( 75 cases). The risk of cancer was analysed by primary site, type of work, years since first exposure, and age at diagnosis. The only significantly increased risks were those of lung cancer among men (SIR 130, 95\% CI 100167 , cohorts $A$ and $B$ combined), and skin cancer among glass blowers (SIR 625, 95\% CI 129-1827). An increased risk of lung, stomach, and colon cancer as well as of brain tumours has been reported in previous studies. It is postulated that the excess risk of lung cancer, detected in this study, can also be accounted for by lifestyle, and not only by possible occupational exposures, because a similar excess risk of lung cancer has been found previously for all industrial workers in Finland. Although the risk of stomach cancer in this study was increased among glass blowers, it was not high in the largest groups of plain glass workers. The risks of tumours of the central nervous system and colon were not increased either.
\end{abstract}

\footnotetext{
Finnish Cancer Registry, Helsinki, Finland

R Sankila, S Karjalainen, E Pukkala, H Oksanen, T Hakulinen, L Teppo, M Hakama

Department of Public Health, University of Tampere, Finland

H Oksanen, M Hakama

Department of Statistics, University of Helsinki, Finland

T Hakulinen
}

Little of a definitive nature is known about the risk of cancer for glass factory workers, although several potential carcinogens, such as arsenic, asbestos, and chromium, are used or have been used in the production of glass. ${ }^{1}$ There are two Swedish casereferent studies in which an increased risk of death from cancers of the lung, ${ }^{12}$ stomach, ${ }^{12}$ and colon ${ }^{2}$ were found. The International Agency for Research on Cancer monograph Silica and some silicates ${ }^{3}$ refers to only one study indicating a raised risk of lung cancer among glass workers. ${ }^{4}$ Among men a significant positive association was found between mortality from lung cancer and glass manufacturing in Alameda County, California. ${ }^{5}$ In a Nordic register linkage study of occupational groups exposed to silica dust an increased risk of lung cancer was detected among Danish glass workers, but not among men in the other Nordic countries working in manufacture of glass, porcelain, ceramics, and tiles. ${ }^{6}$ In a casecontrol study conducted in urban Shanghai the largest excess risk of lung cancer found for women was among glass products workers. ${ }^{7}$ There are Swedish census based record linkage studies indicating significantly increased risks for meningiomas ${ }^{8}$ and gliomas ${ }^{9}$ among Swedish glass, porcelain, or ceramic workers. A high risk of brain cancer among workers manufacturing glass products has also been reported in Illinois. ${ }^{10}$

The purpose of this cohort study was to assess the risk of cancer among workers in the plain glass manufacturing industry.

\section{Subjects and methods}

The workers in two glass factories (A and B) in southern Finland were followed up for incidence of cancer in 1953-86. The cohorts were formed using the factory's employment records. Only workers with at least three months of continuous employment were included.

Cohort A was collected in 1973, and consisted of 2614 workers ( 1353 men, 1261 women) who had been employed between 1 January 1953 and 31 December 1971 , although employment may have started earlier. The workers in this factory were divided into three occupational subgroups: (1) those who had worked at some time as traditional glass blowers, (2) those not 
included above but who had worked at some time as automated glass blowers, and (3) all other glass factory workers.

Cohort B was collected in 1979, and consisted of all workers who had been employed between 1 January 1941 and 31 December 1977. After excluding those dead before the start of the follow up ( 1 January 1953), the size of the cohort was 1135 workers ( 450 men, 685 women). Factory $B$ had not produced blown glass, and hence, no subgrouping of occupations was performed. Fibre glass production workers were excluded.

The observed numbers of cancer cases were obtained from the files of the Finnish Cancer Registry. The follow up commenced three months after the start of employment, and only cancers diagnosed between 1 January 1953 and 31 December 1986 (the closing date for the study) were accepted. The Registry data cover virtually all cancer cases diagnosed in Finland during the study period. ${ }^{11}$ The members of the cohorts were followed up for death and emigration by a record linkage to the National Population Register and the Central Statistical Office. The follow up was complete.

The expected numbers of cancers were calculated on the basis of the person-years at risk, and sex, age, and period specific incidence rates for the whole population of Finland. Standardised incidence ratios (SIR) were calculated by dividing the observed numbers of cases by the expected ones. For the significance calculations the numbers of observed cases were assumed to follow a Poisson distribution.

\section{Results}

The 1803 men in cohorts $A$ and B produced 43473 years of follow up (table 1). During the study period, 163 cancers were diagnosed $v 162.4$ expected (SIR 100 , table 2). The risk of lung cancer was the only one significantly increased (SIR 130, 95\% CI 100-167). The risk of skin cancer (other than melanoma and basalioma) was increased (SIR 143) and the risk of colon cancer was decreased (SIR 34, table 2).

The 1946 women in cohorts A and B (50 876 follow up years, table 1) had a significantly decreased overall cancer risk (SIR 78, 95\% CI 66-92, table 2), concentrated particularly on those primary sites for which there were no hypotheses on possible occupational hazards, grouped here as "other sites." Also, the risk of malignancies of the central nervous system was significantly low (SIR 17). The risk of skin cancer (other than melanoma and basalioma) was increased (SIR 162). No significantly increased risks were found (table 2).

The risk of stomach cancer was slightly increased (SIR 110) in cohort A (men and women combined, table 3). The increase was concentrated in glass blowers using oral (SIR 216) and automated (SIR 226) methods, but the numbers of cases were few, and increased risk was not found among other glass workers in cohort A (SIR 93) or in cohort B (SIR 68, table 3).

The risk of lung cancer was increased among glass blowers using automated methods (SIR 160), as well as among other glass workers in cohort A (SIR 133) and in cohort B (SIR 134), but not among oral glass blowers (SIR 85, table 3). On the other hand, the risk of skin cancer (other than melanoma and basalioma) was high among glass blowers (SIR 625), and in cohort B (SIR 185), but not among other glass workers in cohort A (SIR 76, table 3). The risk of basaliomas was increased among men in cohort $B$ (SIR 276, 95\% CI 158-448), but not among men in cohort A (SIR 51), or among women in either of the cohorts (SIRs 91 and 87).

Stratification by sex, cohort, occupational subgroups, years since first exposure, age, or periods of follow up did not produce any further information on the risks.

\section{Discussion}

Unfortunately, for this study no specific recorded data on working conditions and exposures in the past were available. General information was obtained by interviewing current staff in the technical laboratory and in the production management department. General methods in the production of glassware and containers do not usually differ much from plant to

Table 1 Number of persons and person-years of follow up (P-Y) in two cohorts of glass factory workers in $1953-86$ by type of work and sex

\begin{tabular}{|c|c|c|c|c|c|c|}
\hline & \multicolumn{2}{|l|}{ Men } & \multicolumn{2}{|c|}{ Women } & \multicolumn{2}{|l|}{ All } \\
\hline & No & $P-Y$ & No & $P-Y$ & No & $P-Y$ \\
\hline $\begin{array}{l}\text { Cohort A } \\
\text { Glass blowers using: }\end{array}$ & 1353 & 31945 & 1261 & 31018 & 2614 & 62963 \\
\hline $\begin{array}{l}\text { (a) oral methods } \\
\text { (b) automated methods } \\
\text { Other glass workers }\end{array}$ & $\begin{array}{r}140 \\
61 \\
1152\end{array}$ & $\begin{array}{r}3548 \\
1641 \\
26756\end{array}$ & $\begin{array}{r}\overline{34} \\
1227\end{array}$ & $\begin{array}{r}9 \overline{26} \\
30092\end{array}$ & $\begin{array}{r}140 \\
95 \\
2379\end{array}$ & $\begin{array}{r}3548 \\
2567 \\
56848\end{array}$ \\
\hline $\begin{array}{l}\text { Cohort B } \\
\text { Cohorts A and B }\end{array}$ & $\begin{array}{r}450 \\
1803\end{array}$ & $\begin{array}{l}11528 \\
43473\end{array}$ & $\begin{array}{r}685 \\
1946\end{array}$ & $\begin{array}{l}19858 \\
50876\end{array}$ & $\begin{array}{l}1135 \\
3749\end{array}$ & $\begin{array}{l}31386 \\
94349\end{array}$ \\
\hline
\end{tabular}


Table 2 Observed (Obs) and expected (Exp) numbers and SIRs (95\% CI) of cancers at selected sites among glass factory workers by sex in 1953-86 (cohorts $A$ and $B$ combined)

\begin{tabular}{|c|c|c|c|c|c|c|c|c|c|c|}
\hline \multirow[b]{2}{*}{ Site (ICD 7 code) } & \multicolumn{4}{|l|}{ Men } & \multicolumn{3}{|c|}{ Women } & \multicolumn{3}{|l|}{ All } \\
\hline & Obs & $\operatorname{Exp}$ & \multicolumn{2}{|c|}{$\operatorname{SIR}(C I)$} & Obs & $\operatorname{Exp}$ & $\operatorname{SIR}(C I)$ & Obs & $\operatorname{Exp}$ & $\operatorname{SIR}(C I)$ \\
\hline $\begin{array}{l}\text { All sites (140-204) } \\
\text { Mouth, pharynx (140-148) } \\
\text { Oesophagus (150) } \\
\text { Stomach }(151) \\
\text { Colon }(153) \\
\text { Rectum (154) } \\
\text { Larynx (161) } \\
\text { Lung, pleura (162) }\end{array}$ & $\begin{array}{r}163 \\
3 \\
4 \\
18 \\
18 \\
2 \\
7 \\
3 \\
62\end{array}$ & $\begin{array}{r}162 \cdot 4 \\
6 \cdot 5 \\
2 \cdot 8 \\
20 \cdot 5 \\
5 \cdot 8 \\
5 \cdot 6 \\
4 \cdot 0 \\
47 \cdot 7\end{array}$ & $\begin{array}{r}100 \\
46 \\
143 \\
88 \\
34 \\
125 \\
75 \\
130\end{array}$ & $\begin{array}{l}(85-117) \\
(10-138) \\
(39-366) \\
(52-139) \\
(4-125) \\
(50-256) \\
(15-219) \\
(100-167)\end{array}$ & $\begin{array}{r}140 \\
5 \\
1 \\
16 \\
5 \\
7 \\
7\end{array}$ & $\begin{array}{r}179 \cdot 4 \\
3 \cdot 0 \\
3 \cdot 1 \\
16 \cdot 2 \\
9 \cdot 3 \\
6 \cdot 8 \\
0 \cdot 4 \\
6 \cdot 3\end{array}$ & $\begin{array}{r}78(66-92) \\
167(54-389) \\
32(1-180) \\
99(56-160) \\
54(17-125) \\
103(41-212) \\
\overline{111}(45-229)\end{array}$ & $\begin{array}{r}303 \\
8 \\
5 \\
34 \\
7 \\
14 \\
3 \\
69\end{array}$ & $\begin{array}{r}341 \cdot 8 \\
9 \cdot 5 \\
5 \cdot 9 \\
36 \cdot 7 \\
15 \cdot 1 \\
12 \cdot 4 \\
4 \cdot 4 \\
54 \cdot 0\end{array}$ & $\begin{aligned} & 89(79-99) \\
& 84(36-166) \\
& 85(28-198) \\
& 93(64-129) \\
& 46(19-96) \\
& 113(62-189) \\
& 68(14-199) \\
& 128(99-162)\end{aligned}$ \\
\hline Breast (170) & - & $0 \cdot 2$ & - & - & 39 & $42 \cdot 6$ & $92(65-125)$ & - & - & $-\quad-$ \\
\hline Cervix uteri (171) & $\overline{1}$ & $\overline{1}$ & $\bar{n}$ & - & 10 & $10 \cdot 6$ & $94(45-174)$ & - & - & - \\
\hline $\begin{array}{l}\text { Prostate (177) } \\
\text { Kidney }(180)\end{array}$ & $\begin{array}{r}15 \\
3\end{array}$ & $\begin{array}{r}16 \cdot 7 \\
4 \cdot 1\end{array}$ & $\begin{array}{l}90 \\
73\end{array}$ & $\begin{array}{l}(50-148) \\
(15-214)\end{array}$ & 二 & $\overline{4.5}$ & 二 $=$ & $\overline{3}$ & $\overline{8} \cdot 6$ & $\overline{35} \quad \overline{-102}$ \\
\hline $\begin{array}{l}\text { Kidney }(180) \\
\text { Bladder }\left(181^{\star}\right)\end{array}$ & 7 & 6.8 & 103 & $(41-212)$ & 2 & 2.5 & $\overline{80}(10-289)$ & 9 & $\begin{array}{l}8 \cdot 6 \\
9 \cdot 3\end{array}$ & $\begin{array}{l}35(7-102) \\
97(44-184)\end{array}$ \\
\hline Other skin (191†) & 5 & 3.5 & 143 & $(46-333)$ & 6 & 3.7 & $162(60-353)$ & 11 & $7 \cdot 2$ & $153(76-273)$ \\
\hline $\begin{array}{l}\text { Central nervous system (193) } \\
\text { Non-Hodgkin's lymphomas }\end{array}$ & 5 & $4 \cdot 1$ & 122 & $(40-285)$ & 1 & $5 \cdot 9$ & $17(0-94)$ & 6 & $10 \cdot 0$ & $60(22-131)$ \\
\hline$(200,202)$ & 2 & $2 \cdot 7$ & 74 & $(9-268)$ & 3 & $2 \cdot 7$ & $111(23-325)$ & 5 & $5 \cdot 4$ & $93(30-216)$ \\
\hline Hodgkin's disease (201) & 2 & $1 \cdot 7$ & 118 & $(14-425)$ & 1 & $1 \cdot 2$ & $83(2-464)$ & 3 & 2.9 & $103(21-302)$ \\
\hline $\begin{array}{l}\text { Leukaemia (204) } \\
\text { Other sites }\end{array}$ & 2 & $4 \cdot 3$ & 47 & $(6-168)$ & 1 & $4 \cdot 3$ & $23(1-130)$ & 3 & $8 \cdot 6$ & $35(7-102)$ \\
\hline $\begin{array}{l}\text { Other sites } \\
\text { Not included abo }\end{array}$ & 23 & 24.9 & 92 & $(59-139)$ & 38 & & $67(48-93)$ & 61 & $81 \cdot 2$ & $75(57-96)$ \\
\hline Basaliomas of the skin & 22 & $17 \cdot 6$ & 125 & $(78-189)$ & 24 & $27 \cdot 0$ & $89(57-132)$ & 46 & $44 \cdot 6$ & $103(76-138)$ \\
\hline
\end{tabular}

^Including ureters and urethra.

† Melanomas and basaliomas excluded.

Table 3 Observed (Obs) and expected (Exp) numbers and SIRs (95\% CI) in certain occupational categories in glass industry for selected sites (sexes combined)

\begin{tabular}{|c|c|c|c|c|c|c|c|c|c|c|}
\hline \multirow[b]{2}{*}{ Category } & \multicolumn{3}{|c|}{ Stomach } & \multicolumn{3}{|c|}{ Lung } & \multicolumn{4}{|c|}{ Skin $\star$} \\
\hline & Obs & $\operatorname{Exp}$ & $\operatorname{SIR}(C I)$ & Obs & $\operatorname{Exp}$ & $S I R(C I)$ & Obs & $\operatorname{Exp}$ & $S I I$ & $R(C I)$ \\
\hline $\begin{array}{l}\text { Cohort A: } \\
\text { Glass blowers using } \\
\text { (a) oral methods } \\
\text { (b) automated methods } \\
\text { Other glass workers } \\
\text { Cohort B } \\
\text { Cohorts A and B }\end{array}$ & $\begin{array}{r}24 \\
6 \\
3 \\
3 \\
18 \\
10 \\
34\end{array}$ & $\begin{array}{r}21 \cdot 8 \\
2 \cdot 6 \\
1 \cdot 4 \\
1 \cdot 2 \\
19 \cdot 3 \\
14 \cdot 7 \\
36 \cdot 5\end{array}$ & $\begin{aligned} & 110(71-158) \\
& 231(85-502) \\
& 216(44-626) \\
& 250(52-731) \\
& 93(55-147) \\
& 68(33-125) \\
& 93(65-130)\end{aligned}$ & $\begin{array}{r}42 \\
5 \\
1 \\
4 \\
37 \\
27 \\
69\end{array}$ & $\begin{array}{r}33 \cdot 8 \\
5 \cdot 9 \\
3 \cdot 4 \\
2 \cdot 5 \\
27 \cdot 9 \\
20 \cdot 2 \\
54 \cdot 0\end{array}$ & $\begin{aligned} & 124(90-168) \\
& 85(28-198) \\
& 29(1-164) \\
& 160(44-410) \\
& 133(93-183) \\
& 134(88-194) \\
& 128(99-162)\end{aligned}$ & $\begin{array}{r}6 \\
3 \\
2 \\
1 \\
3 \\
5 \\
11\end{array}$ & $\begin{array}{l}4 \cdot 4 \\
0 \cdot 48 \\
0 \cdot 25 \\
0 \cdot 23 \\
3 \cdot 9 \\
2 \cdot 7 \\
7 \cdot 1\end{array}$ & $\begin{array}{r}136 \\
625 \\
800 \\
435 \\
76 \\
185 \\
155\end{array}$ & $\begin{array}{r}(50-297) \\
(129-1827) \\
(97-2890) \\
(11-2422) \\
(16-223) \\
(60-432) \\
(77-277)\end{array}$ \\
\hline
\end{tabular}

^Melanomas and basaliomas excluded.

plant. On the other hand, the production of unique art glass requires varying methods and processes, but often the series produced are small and the production periods are short.

In the colouring of glass and in the improvement of the quality of the glass mass several possible carcinogens are or were used, including antimony, arsenic, cadmium, chromium (trivalent), copper, lead, manganese, nickel oxide, and zinc selenite. In the matting of the surfaces of products sulphuric and hydrofluoric acids are infrequently used. In the past, asbestos was widely used as a thermoinsulator in hot structures as well as in protective clothing.

The estimation of past exposures among individual workers in any reliable way is impossible, and is only speculative even among occupational groups. In general, however, the exposures were greater in the 1950 s and 1960 s than in recent years. The occupational safety standards are strict now, and all possible cancer hazards are rigourously regulated. Several of the possible carcinogens mentioned above were used in larger amounts in the making of unique, hand made art and design products, which uses oral glass blowing, but this concerns only a small number of workers. The exposures are limited among workers in the automated processes of tableware or container production. Most likely the workers exposed to the largest quantities of asbestos were construction and maintenance workers rather than those engaged in actual production of glass.

The risk of lung cancer was increased among men (in both cohorts), which is in accord with previous reports. As there are no data on smoking habits of the men in the cohorts, the only comparison that could be made was with Finnish industrial workers in general. There are data indicating that men in manufacturing occupations in Finland smoke more than the general population, and that their risk of lung cancer is 
higher (SIR 129) than that in the general working population. ${ }^{12}$ Thus the risk of lung cancer among male glass factory workers is similar to that of men in manufacturing occupations in general. The confounding effect of cigarette smoking has been estimated not to exceed $30 \%$ for the rate ratios for lung cancer between occupational groups. ${ }^{1314}$ Therefore, the possible excess risk of lung cancer attributable to occupational exposures such as asbestos or arsenic, cannot be extracted from our results.

Contrary to previous reports, ${ }^{28-10}$ the risk of tumours of the central nervous system was not raised (table 2), and the risk of colon cancer was low. Glass manufacturing itself, however, is unlikely to have a protective effect against cancer of the colon. Rather, the expected number, based on the incidence of the total population, may be too high for this cohort, which belongs to a socioeconomic class with a low incidence of colon cancer. ${ }^{15}$

The relative risk of stomach cancer was increased among all glass blowers, but not among other glass workers in cohorts A and B (table 3 ). The speculation about glass blowers' direct oral exposure to various metallic compounds as an aetiological factor ${ }^{2}$ was only weakly supported by our results, as the number of stomach cancer cases was not more than three among glass blowers using oral methods.

The risk of skin cancer (other than basalioma and melanoma) was consistently increased among men and women in both cohorts. The reporting of basaliomas is incomplete and they were not included in the figures when total cancer risks were calculated for the general population. To our knowledge there are no reports on an increase in the risk of skin cancer among glass blowers, although hypothetically the increased risk could be work related, owing, for example, to exposure to arsenic.

If the incidence rates of cancer for industrial workers only had been used, the expected figures for certain primary sites (colon, breast, and prostate) would have been lower, and for some others (lung among men, for example), higher as shown in previous studies. ${ }^{12} 15$ Such figures were only available for the 1970s, however, and for age groups from 25 to 64 . The reasons for the decreased cancer risk among women remain obscure, although the "healthy worker effect"16 17 cannot be ruled out. It is unlikely that our results are essentially influenced by other biases; the follow up time was long enough for cancers caused by occupational exposures to emerge, and the follow up through the National Population Register and Cancer Registry was virtually complete. Owing to the small numbers of cases the confidence intervals were wide and the results inconclusive, as they were in previous studies also.

Our results do not indicate an increased cancer risk among workers in the glass manufacturing industry, with the exceptions of lung and skin cancer (and a borderline increase of stomach cancer among glass blowers). Analyses by specific exposures may still show risk factors, but recent developments towards more automated processes decrease both the number of workers and heavy exposures, and thus probably potential cancer hazards as well (glass blowing using oral methods in factory A ended in 1975, and that part of the factory serves as a museum. The rest of the factory will be closed down in the near future). Further studies in this field in Finland alone may not produce much more useful information because of the small number of workers in the industry and the lack of data on specific previous exposures.

The study was supported by the Finnish Work Environment Fund.

We acknowledge the Ahlström Riihimäen Lasi Oy, previously Riihimäki Glass Factory and Karhula Glass Container Works, for permission to refer to their employee records. We thank Mr Eero Kojonen MSc (Eng) for assistance with the collection of the cohort B data.

Requests for reprints to: Dr R Sankila, Finnish Cancer Registry, Liisankatu 21 B, SF-00170 Helsinki, Finland.

1 Wingren $\mathrm{G}$, Axelson $\mathrm{O}$. Mortality pattern in a glass producing area in SE Sweden. Br J Ind Med 1985;42:41 1-4.

2 Wingren G, Axelson $\mathrm{O}$. Mortality in the Swedish glassworks industry. Scand J Work Environ Health 1987;13:412-6.

3 International Agency for Research on Cancer. Silica and some silicates. IARC monographs on the evaluation of the carcinogenic risk of chemicals to humans. Vol 42. Lyon: IARC, 1987:102.

4 Dubrow R, Wegman DH. Occupational characteristics of cancer victims in Massachusetts: 1971-1973. Cincinnati, Ohio: National Institute for Occupational Safety and Health, 1984. (DHSS (NIOSH) publ No 87-109)

5 Milne KL, Sandler DP, Everson RB, Brown SM. Lung cancer and occupation in Alameda County: A death certificate casecontrol study. Am J Ind Med 1983;4:565-75.

6 Lynge E, Kurppa K, Kristofersen L, Malker H, Sauli H. Silica dust and lung cancer: Results from the Nordic occupational mortality and cancer incidence registers. $J$ Natl Cancer Inst 1986;77:883-9.

7 Levin LI, Zheng W, Blot WJ, Gao YT, Fraumeni JF, Jr. Occupation and lung cancer in Shanghai: A case-control study. Br J Ind Med 1988;45:450-8.

8 McLaughlin JK, Thomas TL, Stone BJ, et al. Occupational risks for meningiomas of the CNS in Sweden. J Occup Med 1987;29:66-8.

9 McLaughlin JK, Malker HS, Blot WJ, et al. Occupational risks for intracranial gliomas in Sweden. J Natl Cancer Inst 1987;78:253-7.

10 Mallin K, Rubin M, Joo E. Occupational mortality in Illinois white and black males, $1979-1984$, for seven cancer sites. Am J Ind Med 1989;15:699-717.

11 Saxen E, Teppo L. Finnish Cancer Registry 1952-1977: twentyfive years of a nationwide cancer registry. Helsinki: Finnish Cancer Registry, 1978:1-47.

12 Pukkala E, Teppo L, Hakulinen T, Rimpelä M. Occupation and smoking as risk determinants of lung cancer. Int J Epidemiol 1983;12:290-6.

13 Asp S. Confounding by variable smoking habits in different occupational groups. Scand J Work Environ Health 1984; 10:325-6.

14 Axclson $\mathrm{O}$, Steenland $\mathrm{K}$. Indirect methods of assessing the effects of tobacco use in occupational studies. $\mathrm{Am} \mathrm{J}$ Ind Med 1988;13:105-18.

15 Rimpclä A, Pukkala E. Cancers of affluence: Positive social class gradient and rising incidence trend in some cancer forms. Soc Sci Med 1987;24:601-6.

16 International Agency for Research on Cancer. Interpretation of negative epidemiological evidence for carcinogenicity. Lyon: IARC, 1985. (IARC sci publ No 65.)

17 Vinni K, Hakama $M$. Healthy worker effect in the total Finnish population. Br J Ind Med 1980;37:180-4.

Accepted 11 June 1990 